\title{
ELECTRIC AND ACOUSTIC DYNAMIC RANGES AND LOUDNESS GROWTH FUNCTIONS: A WITHIN-SUBJECT COMPARISON IN COCHLEAR IMPLANT PATIENTS
}

\author{
Katrien Vermeire ${ }^{1,2, *}$, Dewey Tull Lawson ${ }^{3}$ \\ ${ }^{1}$ C. Doppler Laboratory for Active Implantable Systems, Institute of Ion Physics and Applied Physics, University \\ of Innsbruck, Technikerstrasse 25, A-6020 Innsbruck, Austria \\ ${ }^{2}$ University Department for Otorhinolaryngology and Head and Neck Surgery, University Hospital Antwerp, \\ University of Antwerp, Wilrijkstraat 10, 2650 Edegem, Belgium \\ ${ }^{3}$ Duke University, Department of Physics, Physics Building, Science Drive, Box 90305, Durham, NC 27708, \\ U.S.A. \\ * Current affiliation: University College Thomas More, Jozef De Bomstraat 11, 2018 Antwerpen, Belgium
}

Corresponding author: Katrien Vermeire, University College Thomas More, Jozef De Bomstraat 11, 2018 Antwerpen, Belgium, e-mail: katrien.vermeire@lessius.eu

Source of support: This research was supported by RTI International and Med-El GmbH, Innsbruck, Austria

Abstract

Objectives: (1) To estimate the dynamic range (DR) for electric stimulation by means of acoustic and electric loudness matching; (2) to characterize loudness growth as a function of electric stimulus amplitude across the DR.

Design: Prospective study.

Study Design: Three cochlear implant subjects, with normal hearing in the contralateral ear, participated in this study (ME28, ME-29, ME-30). For each electrode, the upper limit of electric stimulation was loudness matched to three different types of pitch-matched acoustic stimuli. Within the electric DR, the $25 \%, 50 \%$, and $75 \%$ points were loudness matched to the acoustic stimuli to create loudness growth functions.

Results: ME-28's DRs for electric stimulation were constant at 17-18 dB across electrodes. ME-29's and ME-30's DRs were narrower, at around $10 \mathrm{~dB}$. For ME-28 and ME-30, none of the corresponding DRs for matched acoustic stimuli exceeded 50 dB. Only one of ME-29's DRs exceeded 35 dB. Loudness growth functions showed a tendency for basal electrodes to have gentler overall slopes. For relatively high proportions of the DR, the three different types of acoustic stimuli tend to have similar loudness growth slopes. However at low levels, the fewer harmonics, the steeper the loudness growth.

Conclusions: There is qualitative and quantitative agreement but patterns of variation can also be observed.

Key words: cochlear implant $\bullet$ single-sided deafness $\bullet$ dynamic range $\bullet$ loudness growth

GAMAS DINÁMICAS ELÉCTRICAS Y ACÚSTICAS Y FUNCIONES DE CRECIMIENTO DE LA INTENSIDAD SONORA: UNA COMPARACIÓN INTRASUJETO EN PACIENTES CON IMPLANTE COCLEAR

\section{Resumen}

Objetivos: (1) Estimar la gama dinámica (GD) para la estimulación eléctrica mediante la igualdad de la intensidad acústica y eléctrica; (2) caracterizar el crecimiento de la intensidad como una función de la amplitud de un estímulo eléctrico a lo largo de la GD.

Plan: Estudio prospectivo.

Plan del estudio: Tres sujetos con implante coclear, con audición normal en el oído contralateral, participaron en el estudio (ME-28, ME-29, ME-30). Para cada electrodo, el límite superior de estimulación eléctrica era la intensidad igualada a tres tipos diferentes de estímulos acústicos con igualdad de tono. Dentro de la GD eléctrica, los puntos al 25\%, 50\% y $75 \%$ fueron igualados en intensidad a los estímulos acústicos para crear funciones de crecimiento de intensidad. 
Resultados: Las GD para la estimulación eléctrica de ME-28 estuvieron constantes a 17-18 dB a través de los electrodos. Las GD de ME-29 y ME-30 fueron más reducidas, alrededor de $10 \mathrm{~dB}$. Para ME-28 y ME-30, ninguna de las GD correspondientes para los estímulos acústicos igualados superó los $50 \mathrm{~dB}$. Solo una de las GD de ME-29 superó los $35 \mathrm{~dB}$. Las funciones de crecimiento de intensidad mostraron una tendencia de los electrodos basales a tener pendientes más suaves en general. Para proporciones relativamente altas de la GD, los tres tipos diferentes de estímulos acústicos tienden a tener pendientes de crecimiento de intensidad similares. Sin embargo, en los niveles bajos, cuanta menos armonía hay, más inclinado es el crecimiento de intensidad.

Conclusiones: Hay una concordancia cualitativa y cuantitativa, pero también se pueden observar patrones de variación.

Palabras clave: implante coclear • sordera unilateral • gama dinámica • crecimiento de intensidad

\section{ЭЛЕКТРИЧЕСКИЕ И АКУСТИЧЕСКИЕ ДИНАМИЧЕСКИЕ ДИАПАЗОНЫ И ФУНКЦИИ УВЕЛИЧЕНИЯ ГРОМКОСТИ: ВНУТРИ ПРЕДМЕТНОЕ СРАВНЕНИЕ У ПАЦИЕНТОВ С КОХЛЕАРНЫМИ ИМПЛАНТАМИ}

\section{Резюме}

Цели: (1) Оценить динамический диапазон (ДД) электростимуляции с помощью выравнивания акустической и электрической громкости; (2) схарактеризовать рост громкости как функцию электрической стимулирующей амплитуды на динамическом диапазоне.

Конструкция: Предполагаемые изучения

Построение исследования: Три человека по кохлеарной имплантации с нормальным слухом в контралатеральном ухе, которые взяли участие в этом исследовании (МЕ-28, ME-29, ME-30). Для каждого электрода верхний лимит электростимуляции - это громкость, приспособлена к трем разным видам акустических стимулов, настроеных на высоту тона. В электрическом динамическом диапазоне, точки $25 \%, 50 \%$, и $75 \%$ имели громкость, приспособленную к акустическим стимулам, чтобы вызвать функции увеличения громкости.

Результаты: Динамические диапазоны МЕ-28 электростимуляции были неизменные при 17-18 дБ на электродах. Динамические диапазоны ME-29 и МЕ-30 были уже - приблизительно на 10 дБ. В случае МЕ-28 и МЕ-30 ни один из соответствующих динамических диапазонов для отрегулированных акустических стимулов не превысил 50 дБ. Только один из динамических диапазонов МЕ-29 превысил 35дБ. Функции увеличения громкости показали склонность основных электродов к более плавным общим снижениям. В случае относительно высоких пропорций динамического диапазона, три разные виды акустических стимулов имели тенденцию к подобным снижениям увеличения громкости. Однако на низких уровнях - чем меньше гармония, тем более крутой рост громкости.

Заключение: Имеется качественное и количественное соответствие, но можно также проследить примеры отклонения.

Ключевые слова: кохлеарный имплант •односторонняя глухота • динамический диапазон • увеличение громкости

\section{Background}

Cochlear implant (CI) speech processors compress a wide dynamic range (DR) of sounds into a much smaller electric DR. The DR of CI recipients is markedly reduced compared with that of normal hearing individuals. Specifically, the psychophysical DR of CI recipients is much smaller (6 to $30 \mathrm{~dB} \mathrm{HL}$ ) compared to that of normal hearing listeners, which is approximately $120 \mathrm{~dB}$ HL for acoustic stimuli. The discrepancy between acoustic and electric DRs requires that signal processing maps the amplitude of the acoustic signal onto the more limited electric DR. Potential implications of such compression are suboptimal speech recognition, particularly in noise, and negative effects on sound quality. Currently there is little agreement on the shape of the loudness growth function in electric hearing. If the acoustic-to-electric amplitude mapping fails to maintain appropriate loudness growth within each electrode, important speech cues may be lost. Previous studies have shown that the best speech recognition occurs when a normal loudness growth function is restored (Holden et al., 2007; Davidson et al., 2009). Distortions to the normal loudness growth function result in a moderate, but significant drop in speech perception performance (Boëx et al., 1997; Fu \& Shannon, 1998). In all current clinical systems, the default conversion of acoustic amplitude to electric stimulus amplitude (loudness mapping) is done by mapping functions using a logarithmic shape, and the same mapping law is applied to all channels.

One approach to estimate the optimal acoustic-to-electric amplitude mapping is to directly compare acoustic and electric loudness growth functions. CI users who have residual hearing in the ear contralateral to the implanted ear provide a good model for comparisons of acoustic-to-electric amplitude mapping. Eddington et al. (1978) balanced 
Table 1. Information on the three experimental subjects.

\begin{tabular}{|c|c|c|c|c|c|c|c|}
\hline Subject & $\begin{array}{c}\text { Age at } \\
\text { surgery } \\
\text { [yrs: mo] }\end{array}$ & $\begin{array}{l}\text { Duration of } \\
\text { deafness at } \\
\text { surgery [yrs] }\end{array}$ & Aetiology & Implant & Side & $\begin{array}{l}\text { PTA of the non- } \\
\text { implanted ear } \\
\text { [dB HL] }\end{array}$ & $\begin{array}{l}\text { Duration of } \\
\text { implant use } \\
\text { [mo] }\end{array}$ \\
\hline ME-28 & $38: 2$ & 2.5 & Labyrinthitis & COMBI $40+M$ & Left & 17 & 21 \\
\hline ME-29 & 59: 1 & 5.5 & Hydrops & $\begin{array}{l}\text { PULSARCI100 } \\
\text { FLEXSOFT }\end{array}$ & Left & 17 & 7 \\
\hline ME-30 & 22: 11 & 2.5 & Sudden hearing loss & $\begin{array}{l}\text { PULSARCI100 } \\
\text { FLEXSOFT }\end{array}$ & Right & 13 & 18 \\
\hline
\end{tabular}
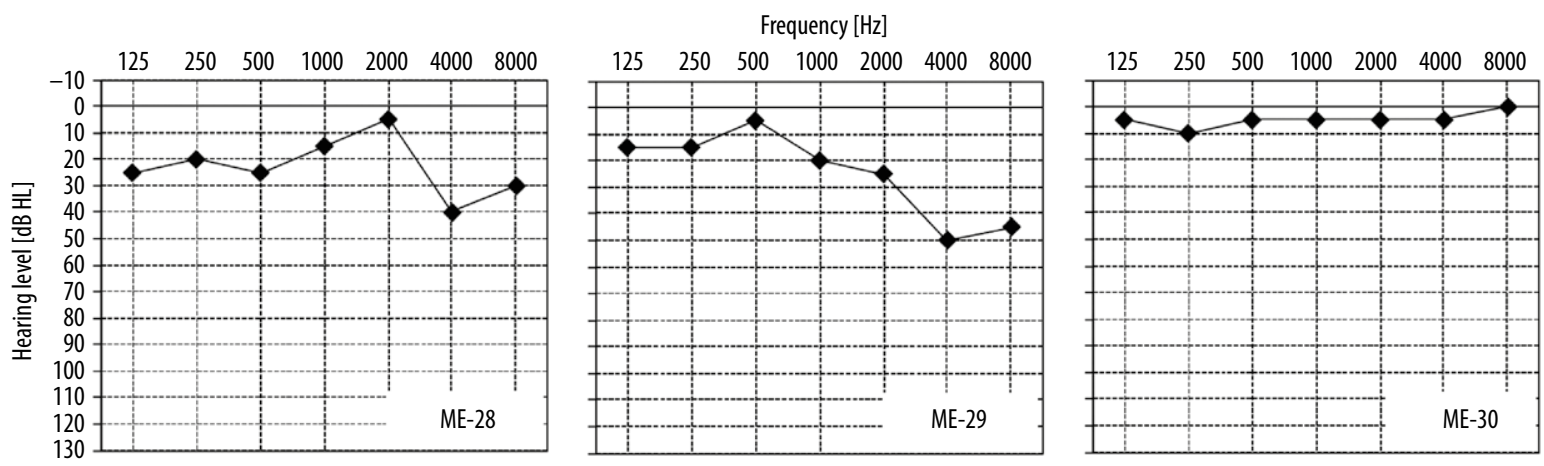

Figure 1. Individual audiograms showing unaided hearing in the non-implanted ear.

loudness between acoustic and electric stimulations in a unilaterally deaf Ineraid CI patient (the device was previously manufactured by Symbion, Inc., of Salt Lake City, UT, and then by Smith \& Nephew Richards, Inc., of Bartlett, TN, but it is no longer manufactured). They found that the acoustic level (in dB SPL) was linearly related to the electric amplitude in $\mathrm{mA}$. A similar logarithmic relation was also observed in another Ineraid user with hearing thresholds less than $50 \mathrm{~dB}$ HL for frequencies less than 500 $\mathrm{Hz}$ (Dorman et al., 1993). The same was observed in three auditory brainstem implant recipients who had substantial acoustic hearing in one ear (Zeng \& Shannon, 1992). Zeng \& Shannon argued that this logarithmic acousticelectric loudness relation is due to the loss of the implanted cochlea's normal logarithmic compression. Based upon this linear relationship between acoustic amplitude (in $\mathrm{dB}$ SPL) and electric current (in $\mathrm{mA}$ ), Zeng and Shannon proposed an exponential model of loudness growth in electric stimulation. The data from these previous studies suggest that loudness growth in CIs could be described by a power function for lower frequencies and an exponential function for high frequencies (Zeng \& Shannon, 1994). However, Hoth (2007) showed that CI recipients demonstrate no systematic dependence of the shape and the steepness of the growth function on electrode position.

The current study evaluates electric-acoustic amplitude mapping in a unique subject group with normal hearing in the non-implanted ear. The fact that these subjects have normal hearing in the non-implanted ear makes them especially suitable for comparing electric-acoustic stimuli, as there is little or no influence of hearing impairment in the non-implanted ear.

\section{Methods}

\section{Subjects}

Three subjects were included in this study. All three participated in a larger study investigating the effectiveness of cochlear implantation in treating unilateral tinnitus (Van de Heyning et al., 2008). All subjects were adults with unilateral severe tinnitus concurrent with ipsilateral sensorineural deafness. It is worth noting that the tinnitus treatment was highly successful and subjects did not suffer from tinnitus during these experiments. Subjects were instructed to notify the experimenter if tinnitus were to resume during the experiment. When this occurred, the experiment was paused. The experiment was resumed when the tinnitus had disappeared. Background information for the three subjects is provided in Table 1 . Clinical pure-tone audiograms for the non-implanted normal ear are shown in Figure 1.

\section{Materials}

All subjects received Med-El cochlear implants (Med-El GmbH, Innsbruck, Austria). ME-28 had the COMBI 40+ with $M$ electrode array and ME-29 and ME-30 had the PULSAR $_{\mathrm{CI}}{ }^{100}$ with FLEX ${ }^{\text {SOFT }}$ electrode array. Both electrode arrays have 12 contacts which are numbered E1 to E12 from apex to base. For both arrays E1 has a distance of $30.4 \mathrm{~mm}$ from the marker ring which indicates full insertion into the cochlea. The inter-electrode distance of the $\mathrm{M}$ electrode is $1.9 \mathrm{~mm}$ which creates a distance of the most basal electrode to the marker ring of $9.4 \mathrm{~mm}$, in contrast to $3.9 \mathrm{~mm}$ with the FLEX ${ }^{S O F T}$ electrode array with a $2.4 \mathrm{~mm}$ inter-electrode spacing. 
Table 2. Mean matched tone pitch (in $\mathrm{Hz}$ ) with Electrode Position using 3 types of acoustic matching tones: fundamental only (pure tone), complex tone with odd harmonics 1-9, and complex tone with all harmonics 1-9.

\begin{tabular}{cccccccccc}
\hline \multirow{2}{*}{ Electrode } & \multicolumn{3}{c}{ ME-28 } & & & ME-29 & & \multicolumn{2}{c}{ ME-30 } \\
\cline { 2 - 10 } & Pure tone & Odd & All & Pure tone & Odd & All & Pure tone & Odd & All \\
\hline 1 & 350 & 330 & 300 & 465 & 440 & 440 & 255 & 197.5 & 190 \\
\hline 2 & 400 & 360 & 300 & 405 & 410 & 380 & 425 & 377.5 & 260 \\
\hline 3 & 450 & 430 & 415 & 435 & 410 & 420 & 435 & 347.5 & 315 \\
\hline 4 & 520 & 515 & 430 & 415 & 410 & 390 & 560 & 500 & 465 \\
\hline 5 & 630 & 630 & 610 & 395 & 430 & 390 & 640 & 600 & 530 \\
\hline 6 & 860 & 710 & 730 & 395 & 430 & 390 & 830 & 695 & 690 \\
\hline 7 & 900 & 965 & 780 & 370 & 410 & 370 & 870 & 737.5 & 660 \\
\hline 8 & 1140 & 1080 & 980 & 387.5 & 410 & 370 & 880 & 695 & 685 \\
\hline 9 & 1240 & 1130 & 1180 & 385 & 370 & 330 & 1150 & 1100 & 820 \\
\hline 10 & 1400 & 1390 & 1340 & 365 & 330 & 310 & 1850 & 1735 & 1740 \\
\hline 11 & 1600 & 1600 & 1850 & 370 & 310 & 290 & 1750 & 1705 & 1755 \\
\hline 12 & 3600 & 3900 & 3300 & 377.5 & 310 & 290 & 3100 & 2710 & 2075 \\
\hline
\end{tabular}

All three subjects were fitted with a TEMPO+ clinical speech processor. The processing strategy used was the CIS+ speech-coding strategy, using $26.7 \mu \mathrm{s} /$ phase (ME-28) or $24.2 \mu \mathrm{s} /$ phase (ME-29 and ME-30) biphasic pulses. The overall bandwidth was 300 to $8500 \mathrm{~Hz}$.

\section{Stimuli}

All electric pulse-burst stimuli were generated in the subjects' implanted receiver-stimulators, under the control of a laboratory interface that in turn received instructions from a digital laboratory processor. Instructions and power were transmitted to the implanted electronics from external antenna coils that were part of the laboratory interfaces. None of the clinical external electronics were involved. Two different interfaces were used, one to control ME-28's Med-El COMBI 40+ implanted electronics and the other to control the Med-El PULSAR ${ }_{\mathrm{CI}}{ }^{100}$ implanted electronics of the ME-29 and ME-30.

The electric stimuli consisted of constant-amplitude pulse trains of $500 \mathrm{~ms}$ duration and a constant pulse rate of $1515 \mathrm{~Hz}$. The pulse duration was $27 \mu \mathrm{s}(\mathrm{ME}-28)$ or $24 \mu \mathrm{s}$ (ME-29 and ME-30). All electric stimuli were delivered in monopolar mode with the reference electrode under the temporalis muscle, as is standard in the COMBI $40+$ and PULSAR $_{\mathrm{CI}}{ }^{100}$. Before the experiments, each subject's electric thresholds and maximum comfortable level (MCL) were checked and loudness balanced.

The acoustic test stimuli consisted of tones with frequencies that were matched to the electric stimuli. This matching was done prior to the experiment and the results are presented in Table 2. For the matching procedure, the subject listened alternately to the electric stimulus and to a loudness-balanced pure tone acoustic stimulus, and adjusted the frequency of the acoustic stimulus to match the pitch of the electric one. Each trial ended when the subject reported that an exact match had been achieved, and 10 trials were conducted for each electrode with various initial settings of the acoustic stimulus. The starting frequencies for matching acoustic tones were varied widely (i.e. the starting point was well below or above the expected match). The acoustic stimuli were $500 \mathrm{~ms}$ in duration. All stimuli were digitally synthesized by laboratory computers, recorded as .wav digital audio files. Stimuli were delivered via an IBM PC compatible computer, using a standard PC sound card and connected to an audiomixer (Mackie Micro Series 1402-VLZ; 14-channel mic/line mixer). Stimuli were presented to the subjects over circumaural headphones (Sony MDR-V600). Three types of acoustic stimuli were used in the loudnessmatching studies: pure tones (fundamental alone), complex tones with odd harmonics 1 through 9 only, and complex tones with all harmonics 1 through 9 . For all the complex tones, the relative amplitude of the $n$-th harmonic was proportional to $1 / n^{2}$. Pure tones (fundamentals only) were included as the simplest pitched stimulus and as a stimulus certain not to cause complex interactions between adjacent processor analysis bands. Versions with only odd harmonics were included to provide some of the additional cues present with all harmonics, but with larger spacing between adjacent partials to decrease such complex interactions between adjacent processor analysis channels.

\section{Procedure}

Throughout the experiment, subjects were asked to adjust the loudness of the acoustic stimulus while the level of the electric stimulus was kept constant. The electric stimulus was delivered first, followed by the acoustic stimulus presentation. The subject was instructed to indicate if the acoustic stimulus was softer, louder, or equally loud compared to the electric stimulus. The level of the acoustic stimulus was varied by the experimenter in response to the subject's response, in a staircase procedure. The start value for each loudness match was randomized, with one starting point well below the match, one starting point above. Two loudness matches were obtained for each electric-acoustic 
A
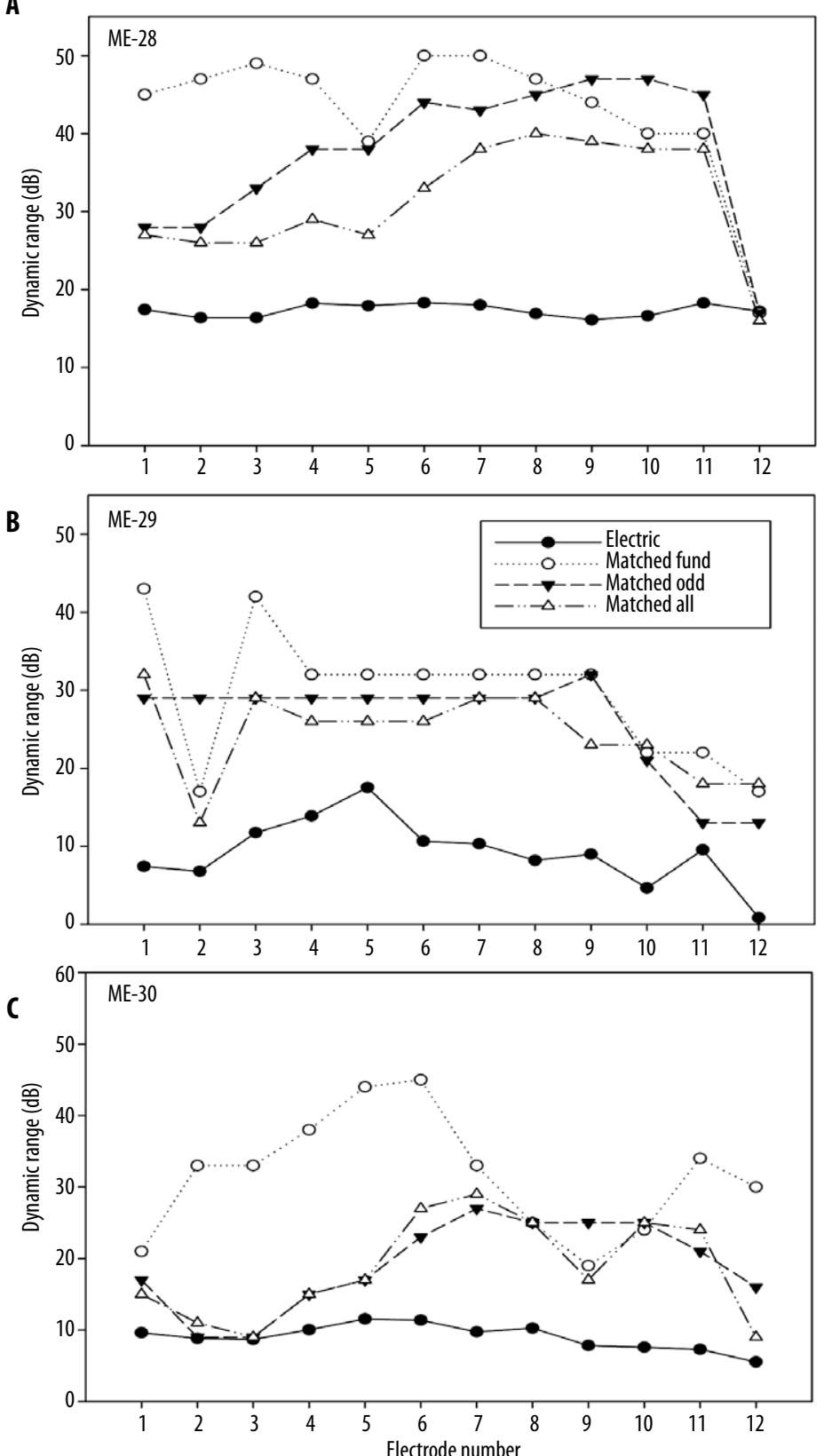

Figure 2. DRs for Subject ME-28 (A), ME29 (B), ME-30 (C). Open and filled symbols show DR mean values. combination. For calculation of the DRs, all 12 electrodes were tested. DR for electric stimulation was determined by the difference between the electric current amplitude levels corresponding to threshold and MCL for each electrode. DR for matched acoustic stimuli was determined by the difference between the subject's acoustic thresholds (Figure 1) and MCL at each pitch-matched frequency. For the detailed studies of loudness growth, one relatively apical, one middle, and one basal electrode were chosen for each subject on the basis of the DR measurements. For ME-28, electrode 4 was chosen as representing a large overall dynamic range variation fairly evenly spread across the acoustic stimulus types. Electrode 8 provided a different distribution among types for a similar overall dynamic range variation. Electrode 12 was selected on the basis of its uniqueness in terms of equal dynamic ranges for electric and all three acoustic stimuli. For the same reason, electrodes 3, 5, and 12 were chosen for ME-29 and electrodes 3, 8, and 12 for subsequent studies with ME-30.

Within the electric DR, the $25 \%, 50 \%$, and $75 \%$ points were loudness matched to the acoustic stimuli to create loudness growth functions.

\section{Results}

\section{Dynamic range}

Figure $2 \mathrm{~A}-\mathrm{C}$ show the DRs for the three subjects. The three types of acoustic stimuli (fundamentals, odd harmonics 1-9, and all harmonics 1-9) are included, as well as the DRs for the current amplitudes of the matched electric stimulus pulses. 
A

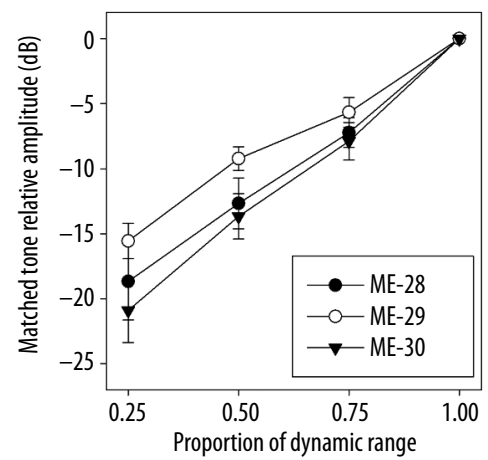

B

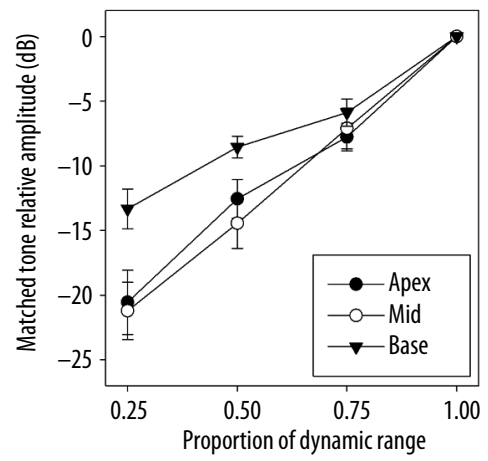

C

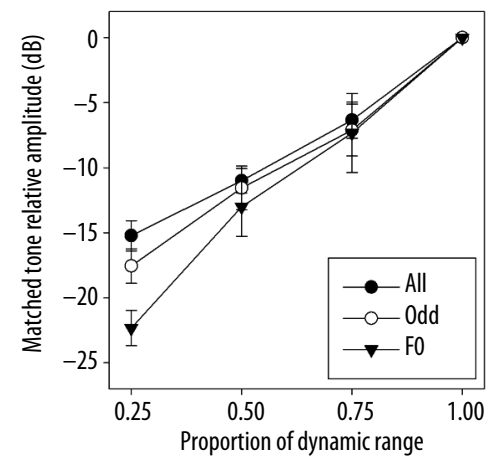

Figure 3. Loudness growth across dynamic range, by subject (A), by electrode position in array (B), and by matching tone type (C).

ME-28's DRs for electric stimulation were roughly constant at $17-18 \mathrm{~dB}$ across electrodes (Figure 2A). The corresponding DRs for matched acoustic stimuli did not exceed 50 $\mathrm{dB}$, and many were much less. There was a substantial difference in matched DR depending on the type of acoustic stimulus, with the DR for pure tone stimuli $(43 \mathrm{~dB})$ tending to be greater than for odd harmonic complex tones (38 $\mathrm{dB}$ ), and both of those greater than for complex tones including all harmonics ( $31 \mathrm{~dB})$. The large drop in ME-28's pure tone DR for electrode 5 was reproducible. The electrode 5 dip in DR was verified by repeating the measurements for electrodes 4,5 , and 6 on a later date. Test-retest reliability was within $3 \mathrm{~dB}$ for all 3 electrodes. For ME-28's electrode 12, all the DRs for the matched acoustic stimuli dropped to equal the $17 \mathrm{~dB}$ DR for electric stimulation.

As seen in Figure 2B, ME-29's DRs for electric stimulation were generally narrower and more variable across electrodes than those observed for ME-28. They varied between 1 and $18 \mathrm{~dB}$. Only two of ME-29's corresponding DRs for matched pure tone stimuli exceeded $35 \mathrm{~dB}$, and some were much less. There was less variation in matched DR with the different types of acoustic stimulus than for ME-28. The rather dramatic drop in the pure tone DR for electrode 2 was reproducible, similar to what was found for electrode 5 in the case of ME-28. Also here, the DR was verified by repeat measurements on a later day.

ME-30's DRs for electric stimulation were roughly comparable to those of ME-29 at around $10 \mathrm{~dB}$, but with less variation across electrodes (Figure 2C). Only one of the corresponding DRs for matched acoustic stimuli approached $50 \mathrm{~dB}$, and some were much less. These DRs were generally narrower than those observed for ME-28, and wider than those observed for subject ME-29. Figure 2C shows more variation in matched DR across the different types of acoustic stimulus for ME-30. The DRs for pure tone stimuli tended to be greater than for odd and all harmonic complex tones, especially for the more apical electrodes.

\section{Loudness growth}

In Figure 3A-C, loudness growth curves are displayed as relative amplitude levels of acoustic stimuli of three types (Fundamental only, Odd harmonics 19-, and All harmonics 19-), matched to current amplitudes corresponding to
$25 \%, 50 \%$, and $75 \%$ of the DRs of each of the three electrodes selected for each of the three subjects. The curves were normalized to matched MCLs in each case. Across all three subjects, the goal was to include choices representing a variety of locations and magnitudes of DRs. As a relatively apical location, electrode 4 was included for ME-28 and electrode 3 for ME-29 and ME-30. As a relatively medial location in the array, electrode 8 was included for ME-28 and ME-30 and electrode 5 for ME29. The most basal electrode, number 12, was included for all three subjects.

The plots in Figure 3A-C allow the opportunity to look for correlations in terms of several variables that might be expected to influence loudness growth. ME-28 and ME30 show steeper slopes than ME-29 (Figure 3A). A tendency of relatively basal electrodes to have gentler overall loudness growth slopes could be observed (Figure 3B). For relatively high proportions of the dynamic range, the three different types of acoustic stimuli tend to have similar loudness growth slopes. However at low levels, the fewer harmonics, the steeper the loudness growth (Figure 3C).

\section{Discussion}

We quantified the DRs of electric stimulation in three subjects. These DRs were roughly between $10 \mathrm{~dB}$ (ME-29 and ME-30) and 20dB (ME-28) (Figure 2). This is in agreement with what is reported in literature (Simmons, 1966; Eddington et al., 1978; Shannon, 1983). Shannon (1983) found that DR is dependent on the stimulation rate, with the DR of high rate stimulation $(1000 \mathrm{~Hz})$ being narrower than the DR at lower stimulation rates $(250 \mathrm{~Hz})(18-25 \mathrm{~dB}$ vs. 30-40 dB). Seeing that in the experiment described here a high rate stimulation $(1515 \mathrm{~Hz})$ is used, this could explain why the DRs that were found are at the lower end of what is reported in the literature, DRs for electric stimulation between 6 and $30 \mathrm{~dB}$.

The DRs found for electric stimulation were matched to acoustic stimulation. This was done in terms of the levels of simple and complex pitch- and loudness-matched acoustic tones heard in the contralateral normal ear. Clearly, the range of loudness experienced by the subjects over the full DR of their electric stimulation did not correspond to a perceptual range of loudness similar to that of 
normal hearing (DR equal to $43 \mathrm{~dB}-30 \mathrm{~dB}-32 \mathrm{~dB}$ for the pure tone stimuli). This finding is in agreement with but slightly smaller than the finding by Zeng and Shannon (1992). They obtained loudness balance values between electric and acoustic stimulation in three auditory brainstem implant listeners who had substantial, even normal, acoustic hearing in the contralateral ear. Their subjects showed a matched DR between 35 and $60 \mathrm{~dB}$. Dorman and colleagues (1993) estimated loudness balance in one Ineraid subject with residual hearing up to $500 \mathrm{~Hz}$. They found a loudness balance value of about $60 \mathrm{~dB}$ when balancing a $250 \mathrm{~Hz}$ acoustic pure tone and an electric $250 \mathrm{~Hz}$ sine signal on electrodes 1 and 2 . A reason for this discrepancy with the present data could be the fact that they used low-rate analog stimulation $(250 \mathrm{~Hz})$ whereas in the present experiment a high-rate pulsatile stimulation burst was used $(1515 \mathrm{~Hz})$. Although the loudness balancing data are reproducible in each condition, substantial variability was seen across subjects, electrodes and their associated pitches, and acoustic tone types. Especially in the case of ME-28 (and also ME-30), there was substantial variation in matched DR depending on the type of the acoustic stimulus involved. A possible explanation for this finding could be that a complex tone including all harmonics has more energy and therefore sounds louder than a complex tone including only odd harmonics and certainly more than pure tone stimuli. In previous reports, loudness balancing experiments were always conducted with acoustic sinusoidal stimuli (Dorman, 1993).

The second part of the current experiment was loudness growth. For that, loudness growth across the DR, as a function of relative amplitude of electric stimulation, was characterized quantitatively. This was done in terms of the levels of simple and complex pitch- and loudness-matched acoustic tones heard in the contralateral normal ear. Results showed that almost half of the 27 measured curves indicated relatively smooth, uniform loudness growth across the full measured range. In roughly one-third of the curves, loudness growth is more rapid at one end of the range than the other, more often at relatively high levels. Only about one-fifth of the curves were more complex, typically including a region of slower growth in the middle of the DR. All of the more complex curves except one were associated with subject ME-30. Hoth (2007) investigated loudness growth functions for electric stimulation in 15 adult Nucleus CI22 or CI24 users. He found that 5 general types of growth functions could be distinguished: (1) a linear growth over the whole DR, (2) a smooth initial growth (positive curvature) followed by a linear growth, (3) an $S$ shaped function starting with positive curvature, (4) an $S$ shaped function starting with negative curvature, and (5) a two-step growth. He could not find any systematic dependence of the shape and steepness of growth function on electrode position. This is not in agreement with the present study. In the present data, relatively basal electrodes tended to have gentler overall loudness growth slopes compared to more medial and apical electrodes (Figure 3B). In a study by $\mathrm{Fu}$ (2005), loudness was balanced at apical and basal electrodes across the electrical dynamic range for both low rate $(100 \mathrm{~Hz})$ and high rate $(1000 \mathrm{~Hz})$ stimuli in six Nucleus CI22 subjects. At the lower stimulation rate of $100 \mathrm{~Hz}, 2$ of the 6 subjects demonstrated a non-linear relationship between the loudness growth functions for the apical and basal electrodes. However, all subjects demonstrated a linear relationship between the loudness growth functions for the apical and basal electrodes at the higher stimulation rate of $1000 \mathrm{~Hz}$. In our experiment, (which stimulated at $1515 \mathrm{~Hz}$ ), we found that the loudness growth function differed between apical and basal electrodes. The explanation for the differences between the results of our experiment and Fu's experiment are unknown. One hypothesis for the difference is that our subjects haved better neural survival in the apex relative to the base, while the neural survival for the patients in Fu's experiments was more homogenous. Fu's subjects haved been deafened for longer duration than ours. Two out of three of our subjects have had a shorter duration of deafness (2.5 years) than the minimum duration of implant use for Fu's subjects. It is safe to assume that Fu's subjects haved been deafened for a greater duration than their implant use.

\section{Conclusions}

Many reproducible measurements have been made based on loudness matching of stimuli between electrically stimulated and normal hearing ears. Consistency has been seen across subjects and patterns of variation across electrode position have been observed. We have confirmed that the electric dynamic range is smaller relative to acoustic dynamic range. We have demonstrated that the loudness growth function is linear across the dynamic range, although the slope may depend on the cochlear location. Research using matching techniques will allow better informed design of processing strategies for auditory prostheses.

\section{Acknowledgments}

We would like to thank the three subjects for their generous and conscientious participation in these studies. We would also like to acknowledge the involvement of colleagues Anne Jackson, Xiaoan Sun, and Robert Wolford in parts of the studies described in this paper, Prof. Paul Van de Heyning for providing the possibility to test the subjects, and Jane Opie and David Landsberger for assistance in preparing the paper. This research was supported by RTI International and Med-El GmbH. This research was approved by the Ethics Committee of the University Hospital Antwerp and the Institutional Review Boards of RTI International, and was carried out in accordance with the Declaration of Helsinki (approval No. OG085). All subjects gave written informed consent prior to participating in the study.

\section{References:}

1. Boëx CS, Eddington DK, Noel VA et al: Restoration of normal loudness growth for CIS sound coding strategies. Abstract, Conference on Implantable Auditory Prostheses, 1997; 26
2. Davidson LS, Skinner MW, Holstad BA et al: The effect of instantaneous Input Dynamic Range setting on the speech perception of children with the Nucleus 24 implant. Ear Hear, 2009; 30: 340-49 
3. Dorman MF, Smith L, Parkin JL: Loudness balance between acoustic and electric stimulation by a patient with a multichannel cochlear implant. Ear Hear, 1993; 14: 290-92

4. Eddington D, Dobelle W, Brackmann D et al: Auditory prosthesis research with multiple channel intracochlear stimulation in man. Ann Otol Rhinol Laryngol, 1978; 87(Suppl): 1-39

5. Fu Q-J, Shannon RV: Effects of amplitude nonlinearity on speech recognition by cochlear implant users and normal hearing listeners. JASA, 1998; 104: 2570-77

6. Fu Q-J: Loudness growth in cochlear implants: effect of stimulation rate and electrode configuration. Hear Res, 2005; 202 : 55-62

7. Holden LK, Skinner MW, Fourakis MS, Holden TA: Effect of increased IIDR in the Nucleus Freedom cochlear implant system. J Am Acad Audiol, 2007; 18: 777-93

8. Hoth S: Indication for the need of flexible and frequency specific mapping functions in cochlear implant speech processors. Eur Arch Otorhinolaryngol, 2007; 264: 129-38
9. Shannon RV: Multichannel electrical stimulation of the auditory nerve in man. I. Basic psychophysics. Hear Res, 1983; 11: 157-89

10. Simmons FB: Electrical stimulation of the auditory nerve in man. Arch Otolaryngol, 1966; 84: 2-54

11. Van de Heyning P, Vermeire K, Diebl M et al: Incapacitating unilateral tinnitus in single-sided deafness treated by cochlear implantation. Ann Otol Rhinol Laryngol, 2008; 117: 645-52

12. Vermeire K, Van de Heyning PH: Binaural hearing after cochlear implantation in subjects with unilateral sensorineural deafness and tinnitus. Audiol Neurootol, 2009; 14: 163-71

13. Zeng F-G, Shannon RV: Loudness balance between electric and acoustic stimulation. Hear Res, 1992; 60: 231-35

14. Zeng F-G, Shannon RV: Loudness coding mechanisms inferred from electric stimulation of the human auditory system. Science, $1994 ; 264:$ 564-66 